Jeronimo Hawellek

\title{
Die persönliche Surrogation
}

Eine vergleichende Untersuchung von Rechtsübergängen zu Regresszwecken in Deutschland, Spanien und England

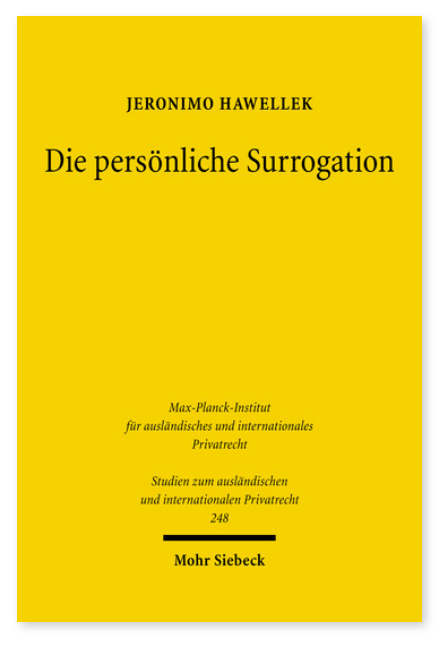

2010. XXIV, 463 Seiten. StudIPR 248

ISBN 978-3-16-151433-3

DOI 10.1628/978-3-16-151433-3

eBook PDF 104,00€

ISBN 978-3-16-150267-5

fadengeheftete Broschur 104,00€
Persönliche Surrogationen findet man in allen großen europäischen Rechtskreisen; die systematische Einbettung in die Zivilrechtsordnung unterscheidet sich jedoch jeweils im deutschen, englischen und spanischen Recht. Jeronimo Hawellek analysiert diese Rechtsfigur in den genannten Rechtsordnungen und zeigt, dass die abweichende Systematik kaum praktische Auswirkungen hat, sieht man von den Besonderheiten der englischen simple subrogation ab, die eine Art Prozessstandschaft darstellt. Der Autor untersucht, was bei der Entscheidung der Sachfragen im Vordergrund steht: dies sind Erwägungen des Schuldnerschutzes und das Ziel, die Subsidiarität nachrangiger Forderungen durchzusetzen. Es zeigt sich, dass die Gleichsetzung der Surrogation mit der Abtretung, die sich nur im deutschen Recht findet, dem Rechtsanwender diese Wertungen gegenüber der Systematik der anderen Rechtskreise erleichtert.

Jeronimo Hawellek Geboren 1976; Studium der Rechtswissenschaft in Hamburg; 2008 Promotion; derzeit Richter in Hamburg.
Jetzt bestellen:

https://mohrsiebeck.com/buch/die-persoenliche-surrogation-9783161514333?no_cache=1

order@mohrsiebeck.com

Telefon: +49 (0)7071-923-17

Telefax: +49(0)7071-51104 